\title{
Exploring the Factors that Impact Students' Transitions to University in Australia
}

\author{
Fangyao Zhang \\ Department of Education, The University of Melbourne, VIC 3010, Australia \\ DOI: $10.32629 /$ jher.v2i6.574
}

\begin{abstract}
There are prominent gaps in educational opportunities and academic outcomes in the Australian education system. The government has made efforts to narrow the gaps and increase the proportion of Australians with higher education qualifications. However, disadvantaged students still lack access to educational opportunities and resources, and are underrepresented in university populations. This essay explores the influential factors that can affect young people's academic and transition outcomes, which involve students' socioeconomic status (SES) backgrounds, engagement in extra-curricular activities and geographical locations. This essay also mainly draws on Bourdieu's theory on social and cultural capital to explain the associations between those factors and students' transitions to university in Australia.

Keywords: transitions to university, social and cultural capital, SES backgrounds, disadvantaged students
\end{abstract}

\section{Introduction}

In Australia, educational inequality is greatly measured in relation to early school leaving and the rate of transitions to higher education. Although there has been a growing rate of transitions to university, educational inequality still exists that not all individuals have access to educational resources and opportunities to pursue a university degree (Cuervo et al., 2019).

There are some influential factors that tend to impact students' academic performance and their transitions to higher education. In this essay, Bourdieu's theory regarding social and cultural capital will be introduced before exploring the factors that can affect young people's transitions to university, which includes students' socioeconomic status (SES) backgrounds, participation in extra-curricular activities, geographical differences, school resources, and school climate.

In this essay, I argue that having higher SES backgrounds and more participation in extracurricular activities and living in urban areas, can exert positive influences on young people's transitions to university. These factors can help young people to have higher aspirations for higher education, academic achievement, and more opportunities to pursue higher education qualification.

\section{Bourdieu's theory: social and cultural capital}

Social capital refers to "the aggregate of the actual or virtual resources related to possession of a durable network of more or less institutionalised relationships of mutual acquaintance and recognition” (Bourdieu, 1986). Bourdieu (1986) regards individuals' possession of social capital as a function that involves the size of social networks and each individual's volume of cultural and economic capital within the social networks.

Cultural capital refers to "the expression of "taste' and display of lifestyle" (Hage, 2013). This concept is often used as a method to differentiate or create the distinction between individuals' social status in society and others (Hage, 2013). According to Bourdieu (1986), cultural capital can be accumulated and passed between families and within communities, which can exert great influence on children's language, knowledge and mannerisms.

\section{Students' socioeconomic (SES) backgrounds}

There is a strong link between students' transitions to higher education and their socioeconomic status (SES). Young people from high socioeconomic backgrounds tend to acquire opportunities to enter university, achieve academic success, and place much emphasis on obtaining higher education qualifications (Vernon et al., 2019). By contrast, socioeconomically disadvantaged students are more likely to obtain substantially lower academic outcomes and drop out of school early.

Socio-disadvantaged backgrounds have been consistently and closely linked to lower confidence, aspirations to higher education as well as academic outcomes (Lamb et al., 2020). High-SES parents are more likely to have high educational aspirations for young people to obtain academic success, which can significantly encourage them to acquire high levels of education (Chesters, 2015; Vernon et al., 2019). The social gaps are apparent that young people from disadvantaged SES families obtain higher education qualifications at a much lower rate than those from advantaged SES families. 
Drawing on the theory of Bourdieu (1973), there is a strong link between the possession of cultural capital and social class. Cultural capital can be transmitted from parents to their children through the socialisation process, in which children are inculcated with the attitudes, preferences, behaviours and habits of their social class (Bourdieu, 1973). Students from advantaged SES backgrounds tend to acquire more cultural capital and class advantage from their parents and thus gain more aspirations and educational opportunities to enter universities.

From a social capital perspective, it is common that young people make use of the resources available in their social networks, which help them to form their educational aspirations and negotiate the transitions to higher education (Briggs et al., 2012; Chesters, 2015). The interaction with parents greatly influences shaping students' developing orientations towards education (Holland et al., 2007). Young people's learning and socialisation heavily rely on collaboration within the family, such as interaction with parents, which can help to maintain and transmit important advantages and disadvantages across generations, including in the sphere of higher education (Chesters, 2015). Students from high SES backgrounds tend to benefit from parental social capital and have university aspirations compared to their peers from low SES backgrounds.

Also, students from high SES backgrounds tend to benefit from parental education, gaining more cultural and social capital from well-educated parents. Parental education plays an important role in young people's levels of education. Having a university-educated parent, young people are more likely to graduate from university (Chesters \& Watson, 2013). The findings indicated that having a university-educated father, male students were almost three times more likely to have acquired a university degree than their male peers, and female students were nearly four times more likely to study in university than other female peers (Chesters \& Watson, 2013). Mother's education also exerted a positive influence on young people's education, although it is slightly less influential than father's (Chesters \& Watson, 2013).

\section{Participation in extra-curricular activities}

There is a positive correlation between participation in structured extra-curricular activities and adolescent development, including increased higher education aspirations, academic achievement, and improved self-esteem (Chesters, 2015). According to Marsh and Kleitman (2002), out-of-school leisure activities, such as watching television and hanging out with friends, is closely linked to lower post-secondary aspirations, whereas out-of-school and in-school structured activities, including recreational programmes and school sports day, is inextricably associated with higher aspirations and educational attainment.

These findings are consistent with the research by Bloomfield and Barber (2011) that young people's participation in a variety of structured extra-curricular activities could exert a positive impact on their social and academic self-concept. In particular, the results present that young people from lower SES backgrounds were more likely to benefit from such activities, as they are provided with opportunities to interact and cooperate with their peers, experience success, and reflect on their future educational aspirations (Bloomfield \& Barber, 2011).

The structured extra-curricular activities enable young people to have peer relationships and friendships, which may increase their educational aspirations and encourage them to acquire high levels of education qualifications. Through participation in extra-curricular activities, young people can connect with their peers from diverse backgrounds with different kinds of skills, resources, interests, and connections, which can enhance the development of youth-derived social capital (Chesters, 2015). Peers can be an important source of information and support. The social capital networks based on peer relationships can provide students with not only a sense of belonging to school but also motivate them to chart their postsecondary transitions and pursue higher levels of educational qualifications (Chesters, 2015).

\section{Geographical differences}

The locational differences can exert a great impact on young people's educational aspirations and transitions to higher education. When rural and regional students consider their post-secondary education, they are more likely to think about the spatial and economic challenges, which can limit their choices and decrease their aspirations to pursue higher education (Cuervo et al., 2019). According to statistics, urban young people who aspire to enrol in the university account for 58\%, compared to $50 \%$ for high access rural peers and $46 \%$ for low access peers (James, 2001).

The geographical location is a significant factor that differs young people's attitudes towards higher education qualifications. Students who live in urban areas emphasise more on acquiring a university degree as an important factor to have high-status careers and earn a high income, while students living in rural and regional areas have fewer interests in pursuing higher education (Abbott-Chapman, 2011; James, 2001). Also, urban students tend to concern more about their parents' expectations. They are more likely to believe that they are expected to enrol in a university course. However, families in rural and regional areas have lower expectations of young people in relation to higher education qualifications, 
compared with families living in major city areas (Abbott-Chapman, 2011).

\section{Conclusion}

In Australia's education system, inequality still persists and exerts a great impact on young people's educational opportunities and levels of education. In this essay, some factors that may impact Australian students' transitions to university have been discussed, which include students' socioeconomic status (SES) backgrounds, participation in extra-curricular activities, geographical differences, school resources, and school climate.

I argue that factors, including higher SES backgrounds, frequent participation in extra-curricular activities, and living in urban areas can positively impact students' academic aspirations and opportunities to acquire higher education qualifications. Although there is an increasing proportion of young people with a university degree, the government and schools should pay more attention to disadvantaged students. Young people who come from lower SES families, live in rural and regional areas tend to be vulnerable to educational disadvantages and drop out of schools early.

\section{References}

[1] Abbott-Chapman, J. (2011). Making the most of the mosaic: Facilitating post-school transitions to higher education of disadvantaged students. The Australian Educational Researcher, 38(1), 57-71. https://doi.org/10.1007/s13384-0100001-9

[2] Blomfield, C. J., \& Barber, B. L. (2011). Developmental experiences during extracurricular activities and Australian adolescents' self-concept: Particularly important for youth from disadvantaged schools. Journal of youth and adolescence, 40(5), 582-594.

[3] Bourdieu, P. (1973). Cultural reproduction and social reproduction. London: Tavistock, 178, 71-112.

[4] Bourdieu, P. (1986). The forms of capital. Cultural theory: An anthology, 1, 81-93.

[5] Briggs, A. R. J., Clark, J., \& Hall, I. (2012). Building bridges: Understanding student transition to university. Quality in Higher Education, 18(1), 3-21. https://doi.org/10.1080/13538322.2011.614468

[6] Chesters, J. (2025). Social capital and aspirations for educational attainment: A cross-national comparison of Australia. Journal of Youth Studies, 19.

[7] Chesters, J., \& Watson, L. (2013). Understanding the persistence of inequality in higher education: Evidence from Australia. Journal of Education Policy, 28(2), 198-215. https://doi.org/10.1080/02680939.2012.694481

[8] Cuervo, H., Chesters, J., \& Aberdeen, L. (2019). Post-school aspirations in regional Australia: An examination of the role of cultural and social capital. The Australian Educational Researcher, 46(5), 843-861. https://doi.org/10.1007/ s13384-019-00305-7

[9] Goe, L. (2007). The link between teacher quality and student outcomes: A research synthesis. Nationalcomprehensive center for teacher quality.

[10] Hage, G. (2013). Eavesdropping on Bourdieu's philosophers. Thesis Eleven, 114(1), 76-93.

[11] Holland, J., Reynolds, T., \& Weller, S. (2007). Transitions, networks and communities: The significance of social capital in the lives of children and young people. Journal of Youth Studies, 10(1), 97-116. https://doi. org/10.1080/13676260600881474

[12] James, R. (2001). Participation disadvantage in Australian higher education: An analysis of some effects of geographical location and socioeconomic status. Higher Education, 42(4), 455472

[13] Lamb, S., Jackson, J., Walstab, A., \& Huo, S. (2015). Educational opportunity in Australia 2015: Who succeeds and who misses out

[14] Marks, G. N. (2010). What aspects of schooling are important? School effects on tertiary entrance performance. School Effectiveness and School Improvement, 21(3), 267-287. https://doi.org/10.1080/09243451003694364

[15] Marks, G. N. (2017). Students in Australian Catholic and Independent schools have more positive learning environments: Evidence from the 2012 PISA study. Journal of School Choice, 11(3), 426-441. https://doi.org/10.1080/155821 59.2017 .1301176

[16] Monks, J., \& Schmidt, R. M. (2011). The impact of class size on outcomes in higher education. The B.E. Journal of Economic Analysis \& Policy, 11(1). https://doi.org/10.2202/19351682.2803

[17] Ning, B., Van Damme, J., Van Den Noortgate, W., Yang, X., \& Gielen, S. (2015). The influence of classroom disciplinary climate of schools on reading achievement: A cross-country comparative study. School Effectiveness and School Improvement, 26(4), 586-611.

[18] Polesel, J., Leahy, M., \& Gillis, S. (2018). Educational inequality and transitions to university in Australia: Aspirations, agency and constraints. British Journal of Sociology of Education, 39(6), 793-810. https://doi.org/10.1080/01425692. 2017.1409101 
[19] Vernon, L., Watson, S. J., Moore, W., \& Seddon, S. (2019). University enabling programs while still at school: Supporting the transition of low-SES students from high school to university. The Australian Educational Researcher, 46(3), 489-509. https://doi.org/10.1007/s13384-018-0288-5

[20] Wang, M.-T., \& Degol, J. L. (2016). School climate: A review of the construct, measurement, and impact on Student Outcomes. Educational Psychology Review, 28(2), 315-352. https://doi.org/10.1007/s10648-015-9319-1

[21] Wang, M.-T., \& Degol, J. L. (2016b). School climate: A review of the construct, measurement, and impact on student outcomes. Educational Psychology Review, 28(2), 315-352. https://doi.org/10.1007/s10648-015-9319-1

[22] Wayne, A. J., \& Youngs, P. (2003). Teacher characteristics and student achievement gains: A review. Review of Educational research, 73(1), 89-122. 